\title{
Description of Sergentomyia phadangensis n. sp. (Diptera, Psychodidae) of Thailand
}

Raxsina Polseela ${ }^{1,2^{*}}$, Jerome Depaquit ${ }^{3}$ and Chamnarn Apiwathnasorn ${ }^{4}$

\begin{abstract}
Background: Since 1996, there are emerging autochthonous cases of leishmaniasis in Thailand due to Leishmania "siamensis" and to L. martiniquensis explaining a recent interest for the sand fly fauna where Sergentomyia gemmea and Se. barraudi have been considered possible vectors in the country.

Methods: Field studies were undertaken in a cave of Phitsanulok Province, Thailand. Phlebotomine sandflies have been studied morphologically and some have been processed for molecular biology (sequencing of cytB rDNA).

Results: A new species of sand fly, belonging to the genus Sergentomyia: Se. phadangensis n. sp., is described. The association of the male and female is supported by the homology of the sequences of cytochrome $b$ rDNA.

Conclusions: The description of a new species in Thailand is of importance in view of the existence of autochthonous leishmaniases.
\end{abstract}

Keywords: Phlebotomus, Sergentomyia, Thailand, Caves, Molecular biology, Systematics

\section{Background}

As it is an area which has long been considered to be free of leishmaniasis, there are few data related to Phlebotomine sand flies in South-Eastern Asia. However, the first autochthonous South-Eastern Asian case of leishmaniasis was discovered in Thailand in 1996, followed by a total of 13 cases due to Leishmania "siamensis" and, surprisingly, to L. martiniquensis [1], a species of the French West Indies, recently described [2]. This new epidemiological datum explains a growing interest in the sand fly fauna of Thailand. A total of 26 species of phlebotomine sand flies have been recorded in this country: one Chinius, three Idiophlebotomus, eight Phlebotomus, one Grassomyia and 13 Sergentomyia [3-6], excluding Nemapalpus vietnamensis not considered to be a sand fly [7] and some doubtful records.

During field work carried out over one year in the Phadang limestone cave, the most abundant species caught - new to Science - is described in the present paper.

\footnotetext{
* Correspondence: raxsinap@nu.ac.th

'Department of Microbiology and Parasitology, Faculty of Medical Science, Naresuan University, Phitsanulok, Thailand

${ }^{2}$ Center of Excellence in Medical Biotechnology, Faculty of Medical Science, Naresuan University, Phitsanulok, Thailand

Full list of author information is available at the end of the article
}

\section{Methods}

Sampling

Field studies were undertaken between February 2010 and January 2011 in Phadang cave in Noen Maprang, Phitsanulok Province, located in the lower northern part of Thailand at $16^{\circ} 30^{\prime} 58.8^{\prime \prime} \mathrm{N}, 100^{\circ} 40^{\prime} 00.5^{\prime \prime} \mathrm{E}$. This limestone cave, situated in a mountainous area, is found in the foothills of a mountain and consists of two asymmetrical caverns. It is estimated to be $15-80 \mathrm{~m}$ wide, $80-100 \mathrm{~m}$ long, and 1-20 m high, and lies at 108 meters a.s.l. The cave may be wet or dry depending on the season and the amount of sunlight it receives. It is accessible to travelers, but is home to many bats.

\section{Mounting}

Phlebotomine sand flies were collected using CDC miniature light traps usually installed overnight from 6 p.m. to 6 a.m. Specimens collected were stored in $96 \%$ ethanol. Some of them were mounted in toto in Hoyer's medium and others for the application of molecular biology techniques. Regarding the latter: head, thorax and genitalia were cut off in a drop of ethanol, cleared in boiling Marc-André solution and, after dehydration, mounted on slides in Canada Balsam. The anterior part 
of the abdomen of each specimen was dried and stored in a vial at $-20{ }^{\circ} \mathrm{C}$, before DNA extraction.

The specimens were observed under a BX53 microscope equipped with a video camera and measured using Stream motion software (Olympus, Japan). The usual keys for the identification of the sand flies from the indo-chinese region have been consulted [8-10]. Drawings were made using a camera lucida. Morphological terminology is that commonly used for Old World sandflies $[4,5,8,10-13]$ and we add the corresponding nomenclature proposed for Diptera [14]. Abbreviations of generic names follow [15]. All measurements are in $\mu \mathrm{m}$.

\section{Molecular analysis}

We decided to sequence a fragment of cytochrome b (Cyt b) which is the most used molecular marker for Phlebotomine sand fly systematic studies [16]. Genomic DNA was extracted individually from the part of the abdomen of sand flies (5 males and 5 females) using the
QIAmp DNA Mini Kit (Qiagen, Germany) following the manufacturer's instructions, modified by crushing the sand fly tissues with a piston pellet (Treff, Switzerland), and using an elution volume of 50 to $200 \mu \mathrm{l}$ [12].

All the mtDNA and rDNA amplifications were performed in a $50 \mu \mathrm{l}$ volume using $5 \mu \mathrm{l}$ of extracted DNA solution and $50 \mathrm{pmol}$ of each of the primers N1N-PDR and C3B-PDR [17]. The PCR mix contained (final concentrations) $10 \mathrm{mM}$ Tris $\mathrm{HCl}(\mathrm{pH} 8.3), 1.5 \mathrm{mM} \mathrm{MgCl}_{2}$, $50 \mathrm{mM} \mathrm{KCl}, 0.01 \%$ Triton X 100, $200 \mu \mathrm{M}$ dNTP each base, and 1.25 units of 5 prime Taq polymerase (Eppendorf, Germany). The cycle begins with an initial denaturation step at $94{ }^{\circ} \mathrm{C}$ for $3 \mathrm{~min}$ and finishes with a final extension at $68{ }^{\circ} \mathrm{C}$ for $10 \mathrm{~min}$. PCRs were done with the following temperature profile: 5 cycles with $30 \sec 94{ }^{\circ} \mathrm{C}, 40 \sec 40{ }^{\circ} \mathrm{C}, 1 \mathrm{~min} 68^{\circ} \mathrm{C}$ and 35 cycles with $30 \sec 94{ }^{\circ} \mathrm{C}, 30 \sec 44^{\circ} \mathrm{C}, 1 \min 68^{\circ} \mathrm{C}$.

Amplicons were analyzed by electrophoresis in $1.5 \%$ agarose gel containing ethidium bromide. Direct

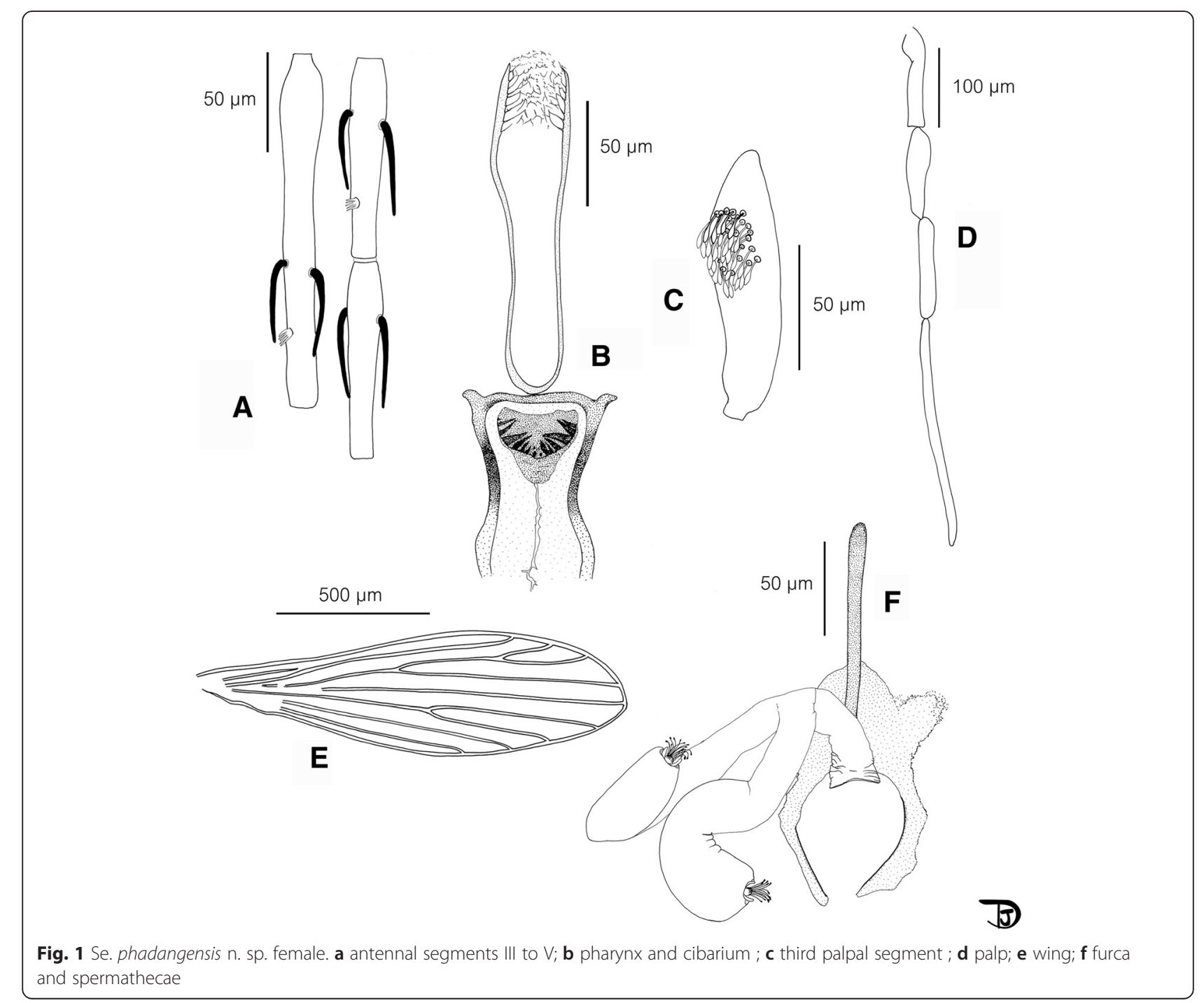




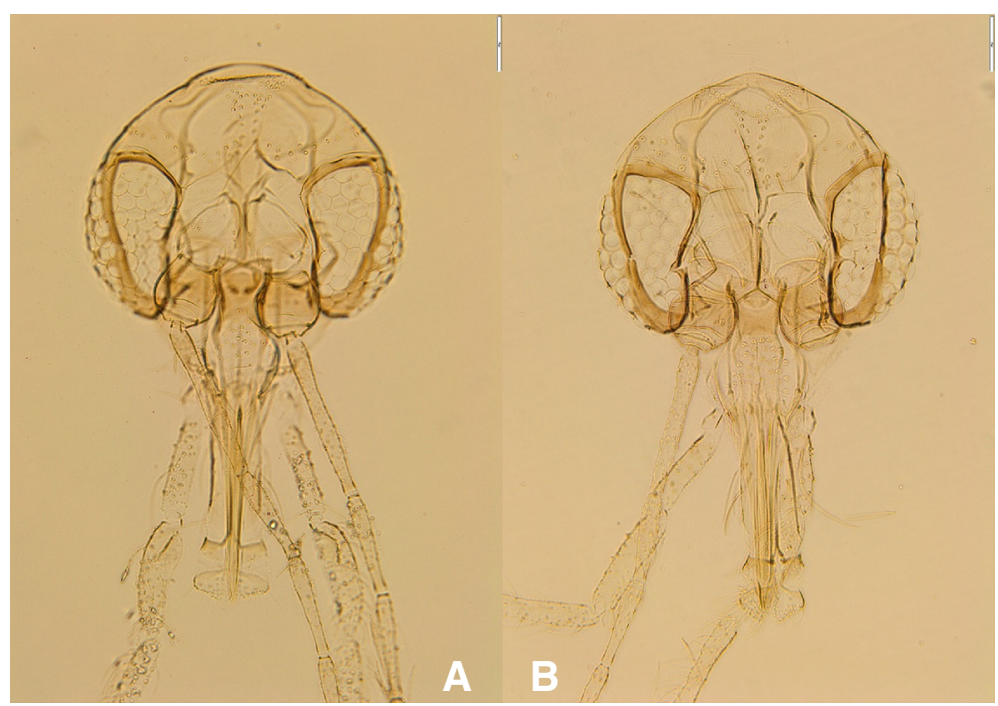

Fig. 2 Heads of the female holotype (a) and of an allotype (THA39) (b)

Table 1 Sergentomyia phadangensis n. sp. females measurements $(n=16)$ in $\mu \mathrm{m}$

\begin{tabular}{|c|c|c|c|c|c|}
\hline & Holotype & Minimum & Maximum & Mean & $\overline{\text { Standard error }}$ \\
\hline Head length & 494 & 487 & 552 & 510.19 & 18.04 \\
\hline Head width & 292 & 290 & 335 & 307.54 & 14.29 \\
\hline Eye length & 155 & 143 & 188 & 158.69 & 12.55 \\
\hline Interocular distance & 132 & 112 & 155 & 135.92 & 13.07 \\
\hline Clypeux length & 92 & 86 & 111 & 97.43 & 8.86 \\
\hline Alll (= flagellomere I, F1) & 165.29 & 140.71 & 165.29 & 158.71 & 8.36 \\
\hline AIV (= flagellomere II) & 98.43 & 82.88 & 98.43 & 90.80 & 4.83 \\
\hline AV (= flagellomere III) & 98.54 & 86.89 & 98.54 & 92.83 & 3.73 \\
\hline labrum-epipharynx (LE) & 188.03 & 172.59 & 201.07 & 185.16 & 8.24 \\
\hline Alll $(=F \mathrm{II}) / \mathrm{LE}$ & 0.88 & 0.77 & 0.89 & 0.85 & 0.04 \\
\hline Palpal segment 1 (P1) & 37.35 & 24.72 & 42.57 & 34.57 & 4.75 \\
\hline Palpal segment 1 (P2) & 94.55 & 84.12 & 99.25 & 91.77 & 4.87 \\
\hline Palpal segment 1 (P3) & 112.75 & 112.75 & 134.73 & 120.08 & 7.48 \\
\hline Palpal segment 1 (P4) & 121.70 & 107.03 & 132.11 & 120.82 & 8.34 \\
\hline Palpal segment 1 (P5) & 273.26 & 192.98 & 340.00 & 261.50 & 42.44 \\
\hline Wing length & 1537.67 & 1383.73 & 1608.35 & 1498.53 & 58.02 \\
\hline Wing width & 460.46 & 400.37 & 492.16 & 447.38 & 27.58 \\
\hline Alpha & 288 & 146.00 & 288.00 & 197.00 & 41.17 \\
\hline Gamma & 276 & 226.00 & 339.00 & 276.82 & 32.73 \\
\hline Delta & 29 & 18.00 & 66.00 & 43.00 & 14.98 \\
\hline $\mathrm{Pi}$ & 389 & 238.00 & 473.00 & 347.18 & 75.09 \\
\hline R5 & 1102 & 1010.00 & 1162.00 & 1083.09 & 48.58 \\
\hline Mesonotum length & 481 & 481.00 & 599.00 & 522.55 & 39.69 \\
\hline
\end{tabular}




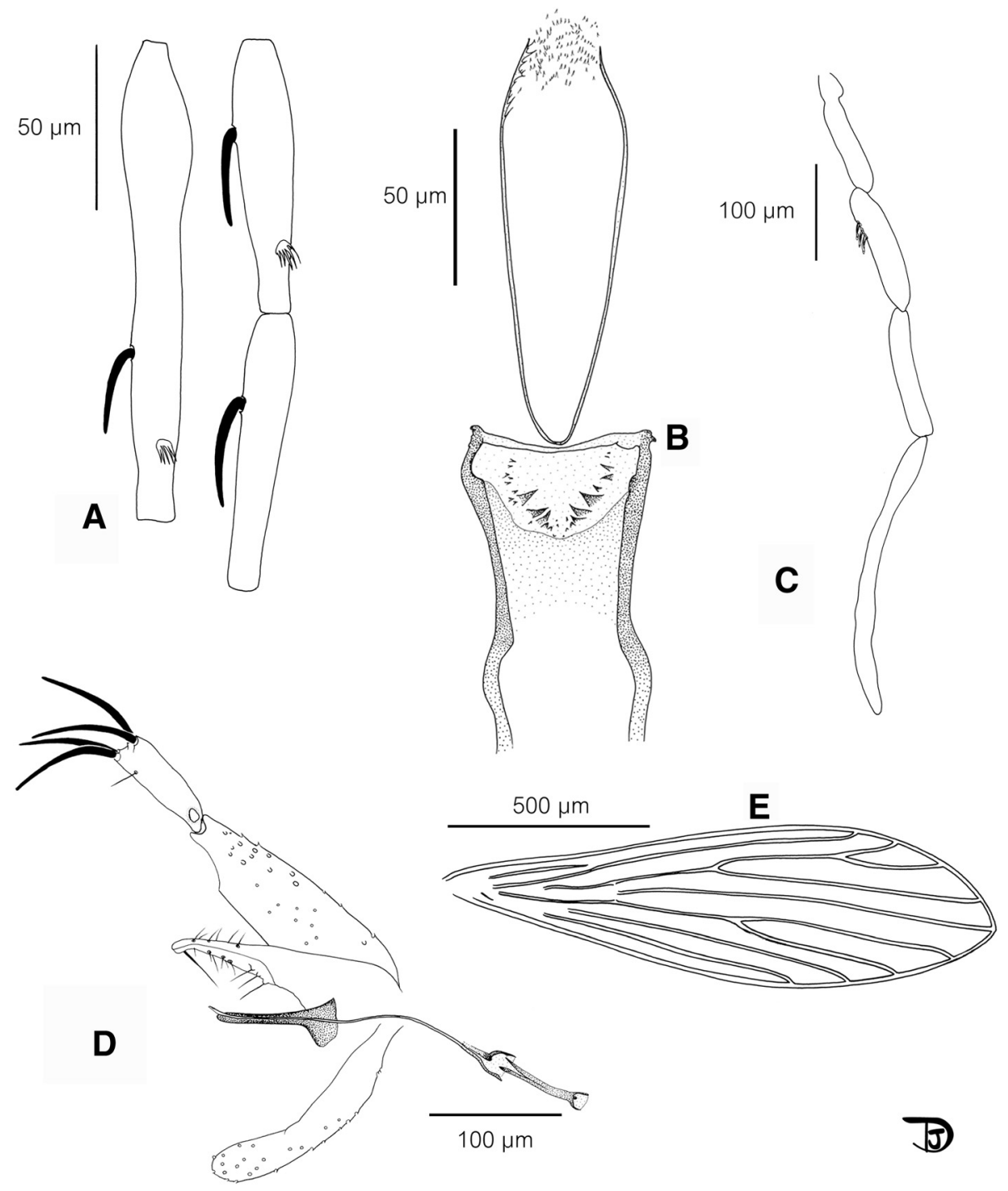

Fig. 3 Se. phadangensis n. sp. male. a antennal segments III to V; b pharynx and cibarium ; c palp ; d genitalia; e wing

sequencing in both directions was performed using the primers used for DNA amplification.

The correction of sequences was done using Pregap and Gap softwares included in the Staden Package [18]. Consensus sequences were aligned by the Clustal W algorithm [19] from the BioEdit 4.8.10 sequence editor [20].

\section{Results}

Molecular analysis

The sequences analysed in the present study have been deposited in Genbank under numbers KT266691 to KT266700. All of them are similar (100 \% homology).

Description of Sergentomyia phadangensis n. sp. Polseela, Depaquit \& Apiwathnasorn

Genus Sergentomyia França \& Parrot, 1920.
Species Sergentomyia phadangensis n. sp. Polseela, Depaquit \& Apiwathnasorn.

\section{Female (Figs. 1 and 2, Table 1)}

The holotype (labelled THA4), and 15 paratypes specimens labelled P1, P2, P3, P4, P5, THA6, THA8, THA9, THA11, THA12, THA13, THA14, THA15, THA16 and THA19 have been examined. The labels refer to the lab where the specimens have been mounted ( $\mathrm{P}$ : Thailand; THA: France).

"Head

Interocular suture complete.

Pharynx narrow. Discrete armature including some little teeth oriented backward.

Cibarium with a very important curved armature consisting of 6 to 8 strong and pointed teeth on each side 
Table 2 Sergentomyia phadangensis n. sp. males measurements $(n=10)$, in $\mu \mathrm{m}$

\begin{tabular}{|c|c|c|c|c|}
\hline & Minimum & Maximum & Mean & Standard error \\
\hline Head length & 460 & 512 & 488.13 & 18.29 \\
\hline Head width & 280 & 337 & 295.00 & 17.65 \\
\hline Eye length & 152 & 169 & 158.44 & 5.15 \\
\hline Interocular distance & 128 & 142 & 132.88 & 4.70 \\
\hline Clypeux length & 95 & 131 & 118.33 & 10.82 \\
\hline Alll (= flagellomere I, F1) & 143.60 & 145.29 & 144.65 & 0.91 \\
\hline AIV (= flagellomere II) & 79.88 & 84.33 & 82.06 & 2.23 \\
\hline AV (= flagellomere III) & 78.80 & 83.08 & 80.94 & 3.02 \\
\hline labrum-epipharynx (LE) & 138.34 & 179.14 & 158.77 & 12.45 \\
\hline Alll $(=F \mathrm{II}) / \mathrm{LE}$ & 0.80 & 0.94 & 0.86 & 0.07 \\
\hline Palpal segment 1 (P1) & 27.18 & 36.87 & 29.88 & 3.42 \\
\hline Palpal segment 1 (P2) & 76.52 & 93.63 & 84.22 & 5.72 \\
\hline Palpal segment 1 (P3) & 104.29 & 120.74 & 114.32 & 5.24 \\
\hline Palpal segment 1 (P4) & 104.39 & 131.83 & 115.34 & 8.28 \\
\hline Palpal segment 1 (P5) & 196.00 & 272.25 & 237.28 & 24.04 \\
\hline Wing length & 1220.00 & 1403.09 & 1321.71 & 73.36 \\
\hline Wing width & 361.28 & 411.61 & 395.36 & 17.52 \\
\hline Alpha & 24.00 & 174.00 & 102.17 & 54.50 \\
\hline Gamma & 227.00 & 268.00 & 252.40 & 15.60 \\
\hline Delta & -98.00 & 66.00 & -9.67 & 61.87 \\
\hline $\mathrm{Pi}$ & 300.00 & 349.00 & 325.60 & 17.39 \\
\hline R5 & 860.00 & 965.00 & 918.60 & 41.36 \\
\hline Mesonotum length & 395.00 & 441.00 & 416.75 & 21.82 \\
\hline Coxite & 193.76 & 214.00 & 202.19 & 6.74 \\
\hline Style & 87.76 & 99.38 & 93.51 & 4.44 \\
\hline Aedeagus & 79.99 & 94.21 & 86.38 & 4.00 \\
\hline Genital pump (GP) & 70.72 & 92.46 & 80.04 & 7.36 \\
\hline Genital filaments (GF) & 201.35 & 239.99 & 221.03 & 12.16 \\
\hline Surstyle (=epandrium) & 143.59 & 194.24 & 164.48 & 18.38 \\
\hline Coxite/surstyle & 1.08 & 1.41 & 1.24 & 0.13 \\
\hline $\mathrm{GP} / \mathrm{GF}$ & 2.47 & 3.00 & 2.77 & 0.20 \\
\hline
\end{tabular}

and a few much smaller median and central ones. All these teeth are darkly pigmented in brown. Sometimes some accessory teeth in the upper and lateral parts of the cibarium. Pigment patch: wide, less pigmented than the teeth, triangular with rounded angles.

Palpal formula: 1, 2, $(3,4), 5$. About forty Newstead's scales club-like in a patch on the basal face of the third segment.

Antennal formula: 2/III-XV. Relatively long ascoids, withour spur, not reaching the next articulation. AIII shorter than AIV + AV.

AIII shorter than the labrum.

Labial furca closed.

*Thorax
No setae on the mesanepisternum (proepimeral, anepisternal or katepisternal).

No pigmentation of mesonotum, pronotum, paratergite, anepisternum, metanotum, posnotum and pleura.

"Spermathecae: smooth and wide. No limit between the body and individual duct. Presence of a common basal duct.

Furca with a long and thin anterior part.

Male (Figs. 2 and 3, Table 2)

Nine paratypes labelled P27, THA31, THA32, THA34, THA36, THA37, THA38, THA39 and THA40 have been examined. The labels refer to the lab where the specimens have been mounted (P: Thailand; THA: France) 


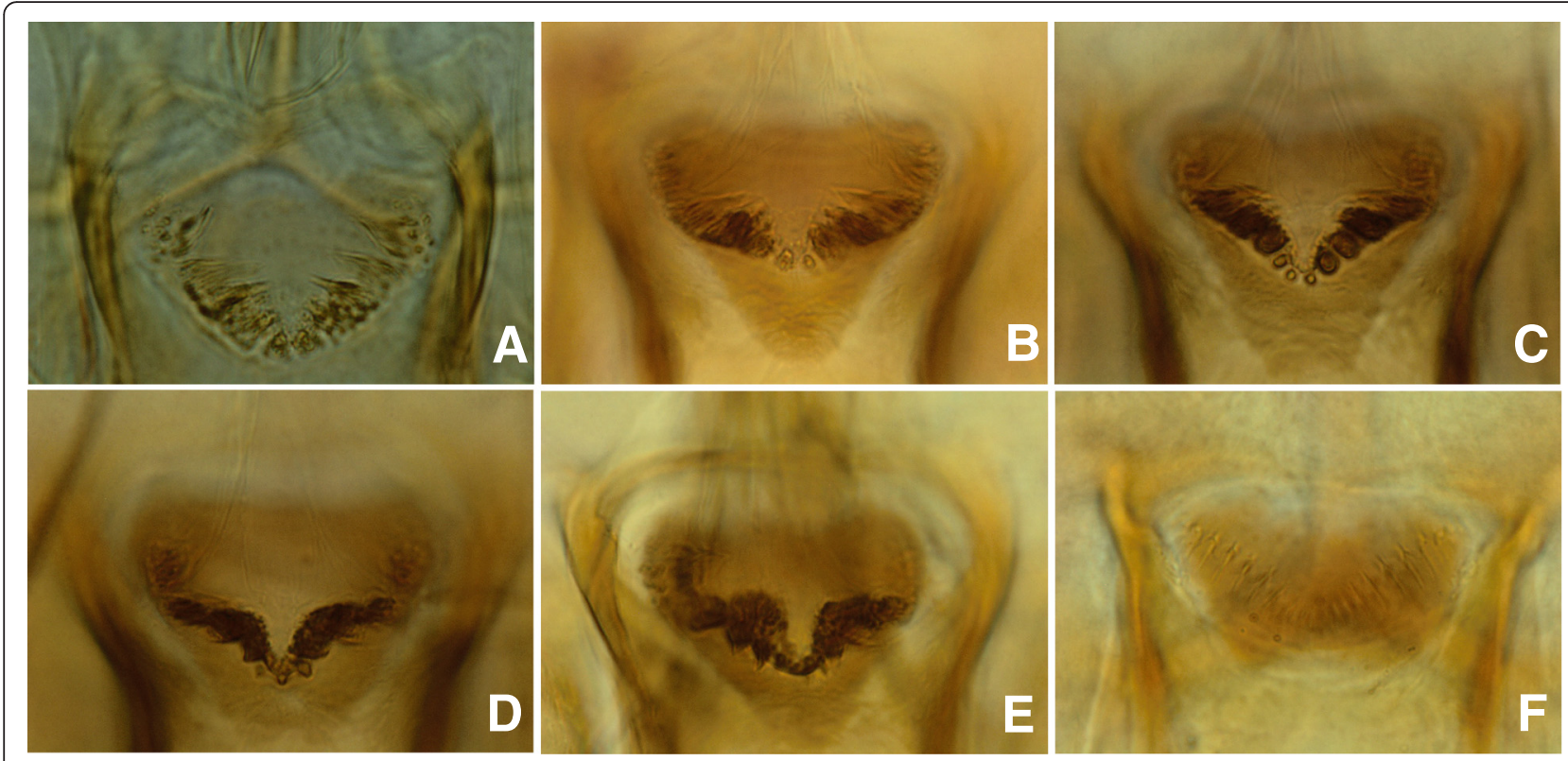

Fig. 4 Cibariums of females of Se. phadangensis n. sp. (a, b, c, d, e) and of Se. dentata from Turkey (f)

*Head

Inter-ocular suture complete.

Cibarium with an important curved armature consisting of three to five large pointed teeth on each side and twelve to twenty denticles along the curve and sometimes outside this line. The latter are observable using the phase contrast option of the microscope.

No trace of a pigmented area could be seen.

Pharynx quite narrow, with a discrete armature composed of small teeth oriented backward.

Palpal formula: 1, 2, (3, 4), 5. A few Newstead's scales on the third palpal segment.

Antennal formula: 1/III-XV. AIII shorter than AIV + AV.

Labial furca closed.

*Thorax

No setae on the mesanepisternum (proepimeral, anepisternal or katepisternal).
No pigmentation of mesonotum, pronotum, paratergite, anepisternum, metanotum, posnotum and pleura.

*Genital Armature

Coxite with a few internal setae not grouped in a tuft.

Style narrow with four terminal spines. The accessory spine is implanted distally (between the distal quarter and third).

Single paramere, curved, with a rounded top.

Surstyle (=epandrium) shorter than the coxite.

Aedeagus straight, finger-like.

Type-locality: Phadang cave located in the lower northern part of Thailand at $16^{\circ} 30^{\prime} 58.8^{\prime \prime} \mathrm{N}, 100^{\circ} 40^{\prime} 00.5^{\prime \prime} \mathrm{E}$, 108 meters above sea level.

The holotype (female) and 10 paratypes ( 5 females and 5 males) have been deposited in the National Science Museum of Pathumthani (Thailand). Fourteen paratypes (ten females and four males) have been

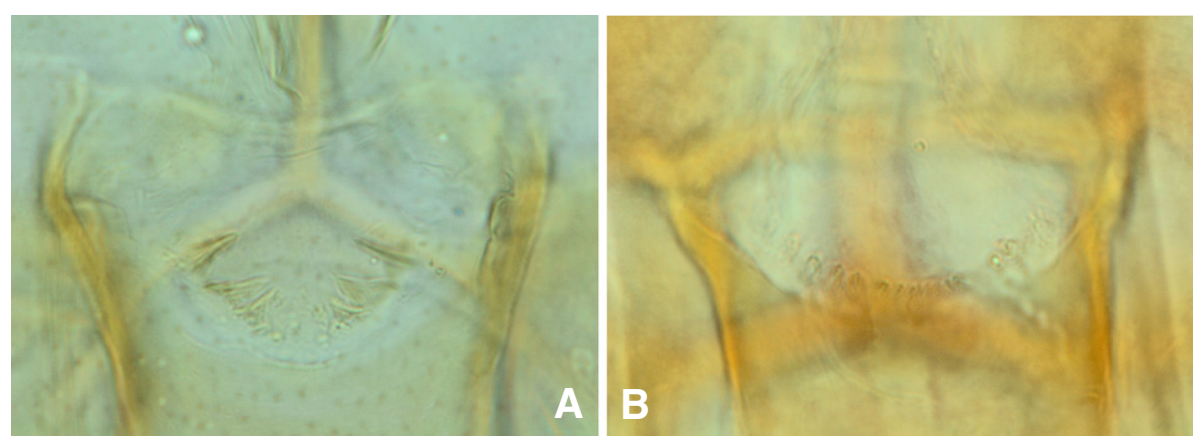

Fig. 5 Cibariums of males of Se. phadangensis n. sp. (a) and of Se. dentata from Turkey (b) 


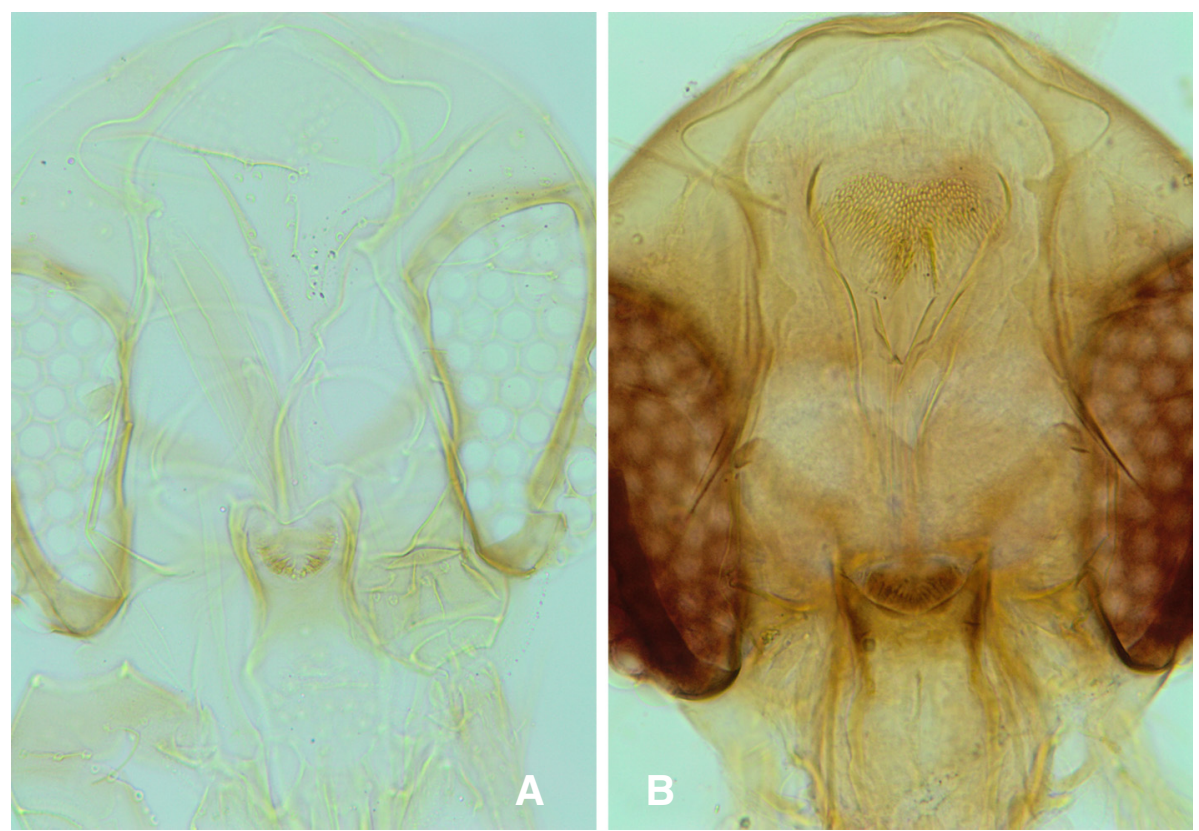

Fig. 6 Pharynx and cibarium of males of Se. phadangensis n. sp. (a) and of Se. dentata from Turkey (b)

deposited in the Museum national d'Histoire naturelle of Paris (France).

Etymology: the name Sergentomyia phadangensis n. sp. is related to the Phadang cave where it has been caught.

In accordance with section 8.5 of the International Code of Zoological Nomenclature, details of the new species have been submitted to ZooBank. The life science identifier (LSID) related to record is urn:lsid:zoobank.org:pub:8920F0C8-79BD-47AA-B367-E052C38 023F9. The LSID for the new name Sergentomyia phadangensis is: urn:lsid:zoobank.org:act:425142C7380D-46B0-8777-33469075C4DC.

\section{Discussion}

For a long time, the species of the genus Sergentomyia were little studied as they were not regarded as vectors of any human leishmaniasis agent. However, some of them have recently been presented as possible vectors of Leishmania responsible for human infection [21], in Thailand too [22].

Sergentomyia is the genus with the greatest known diversity, surpassing the number of species of all other Old World genera (Phlebotomus, Idiophlebotomus, Chinius, Spelaeophlebotomus, Grassomyia, Parvidens, Spelaeomyia and Demeillonius) taken together [23, 24]. The species of the genus Sergentomyia share the following characters: a mesanepisternum without setae, abdominal tergites 2-6 usually carrying all or most recumbent hairs, a usual $1 / \mathrm{III}-\mathrm{XV}$ antennal formula in males and $2 / \mathrm{III}-\mathrm{XV}$ in females with some exceptions, a cibarium with an armature of teeth and/or denticles more developed in females than in males (apart from exceptions), a single paramere, a style with four terminal spines (or often 2 terminal and 2 subterminal ones) and an accessory spine.

The species Se. phadangensis n. sp. exhibits the characters qualifying it for inclusion in the genus Sergentomyia.

Mainly based on the spermathecal morphology, the genus Sergentomyia is subdivided into eight subgenera: Sergentomyia França \& Parrot, 1920; Neophlebotomus França \& Parrot, 1920; Sintonius Nitzulescu, 1931; Parrotomyia Theodor, 1948; Rondanomyia Theodor, 1948; Capensomyia Davidson; Vattieromyia, Depaquit, Léger \& Robert, 2008, and Trouilletomyia Depaquit, Léger \& Randrianambinintsoa, 2014. Moreover, there are a lot of unclassified species within the genus Sergentomyia [25].

Se. phadangensis n. sp. exhibits wide and smooth spermathecae and can therefore be included in the subgenus Sergentomyia.

This new species can be easily differentiated from all the other species recorded in South-Eastern Asia by its highly developed cibarial armature in both females and males. The teeth are bigger and darker than those of the most closely related species, Se. dentata (Figs. 4 and 5). Moreover, the pharynx of Se. dentata is wide with a Se. antennata-like proeminent armature whereas that of Se. phadangensis $\mathrm{n}$. $\mathrm{sp}$. is narrow with a Se. schwetzi-like discret armature (Fig. 6). The record of Se. dentata in Thailand [26] should be checked in the light of the description of this new species. Initially described from Pakistan, Se. dentata is mainly distributed in the Middle-East and the Eastern Mediterranean basin [27]. 


\section{Conclusion}

The description of a new species in Thailand is of importance taking into account the existence of autochthonous leishmaniases caused by $L$. "siamensis" and $L$. martiniquensis. The local transmission of these parasites is not explained, despite the possible role of two Sergentomyia species: Se. gemmea and Se. barraudi.

\section{Abbreviations}

Cyt b: Cytochrome b; Se.: Sergentomyia.

\section{Competing interests}

The authors declare that they have no competing interests.

\section{Authors' contributions}

RP and JD conceived the study; RP and CA performed field collections. RP, JD and CA monted the specimens; JD did the drawings and molecular biology. RP and JD drafted the manuscript. RP, JD and CA contributed to writing the manuscript and have approved the final version. All authors read and approved the final manuscript.

\section{Authors' information}

Nothing more than indicated in the title page.

\section{Acknowledgements}

We thank Véronique Lehrter, Alicia Vol and Mireille Cousinat for their technical help. We are grateful to the Department of National Parks, Wildlife and Plant Conservation (Thailand) for permission to conduct field work at Tham Pha Tha Phon non-hunting area for the collection specimens from the cave.

\section{Author details}

'Department of Microbiology and Parasitology, Faculty of Medical Science, Naresuan University, Phitsanulok, Thailand. ${ }^{2}$ Center of Excellence in Medical Biotechnology, Faculty of Medical Science, Naresuan University, Phitsanulok, Thailand. ${ }^{3}$ Université de Reims Champagne-Ardenne, ANSES, SFR Cap Santé EA4688 - USC «transmission vectorielle et épidémiosurveillance de maladies parasitaires (VECPAR)», 51, rue Cognacq-Jay, 51096 Reims Cedex, France. ${ }^{4}$ Department of Medical Entomology, Faculty of Tropical Medicine, Mahidol University, Bangkok, Thailand.

Received: 8 July 2015 Accepted: 7 January 2016

Published online: 15 January 2016

\section{References}

1. Pothirat T, Tantiworawit A, Chaiwarith R, Jariyapan N, Wannasan A, Siriyasatien $\mathrm{P}$, et al. First isolation of Leishmania from Northern Thailand: case report, identification as Leishmania martiniquensis and phylogenetic position within the Leishmania enriettii complex. PLoS Negl Trop Dis. 2014; 8(12):e3339.

2. Desbois N, Pratlong F, Quist D, Dedet JP. Leishmania (Leishmania) martiniquensis n. sp. (Kinetoplastida: Trypanosomatidae), description of the parasite responsible for cutaneous leishmaniasis in Martinique Island (French West Indies). Parasite. 2014;21:12.

3. Curler GR. Records of phlebotomine sand flies (Diptera, Psychodidae, Phlebotominae) with a description of a new species of Sergentomyia França \& Parrot from Khao Yai National Park, Thailand. Zootaxa. 2011;2806:60-8.

4. Depaquit J, Léger N, Beales P. Chinius barbazani n. sp. de Thaïlande (Diptera: Psychodidae). Parasite. 2006;13(2):151-8.

5. Depaquit J, Muller F, Leger N. Phlebotomus (Euphlebotomus) barguesae $\mathrm{n}$. sp. from Thailand (Diptera - Psychodidae). Parasit Vectors. 2009;2(1):5.

6. Muller F, Depaquit J, Léger N. Phlebotomus (Euphlebotomus) mascomai n. sp. (Diptera-Psychodidae). Parasitol Res. 2007;101(6):1597-602.

7. Hennig W. Insektenfossilien aus der unteren Kreide. IV. Psychodidae (Phlebotominae) mit einer kristischen Übersicht über das phylogenetische System der Familie und die bischer beschriebenen Fossilien (Diptera). Stuttgarter Berträge zur Naturkunde aus dem Staatlichen Museum für Naturkunde in Stuttgart. 1972;241:1-69.
8. Lewis DJ. The phlebotomine sandflies (Diptera: Psychodidae) of the Oriental Region. Bulletin of the British Museum (Natural History), Entomology Series. 1978;37(6):217-343.

9. Lewis DJ. Phlebotomine sandflies (Diptera : Psychodidae) from the Oriental Region. Syst Entomol. 1987;12:163-80.

10. Quate LW. A review of the Indo-Chinese Phlebotominae. (Diptera: Psychodidae). Pacific Insects. 1962;4(2):251-67.

11. Abonnenc E. Les phlébotomes de la région éthiopienne (Diptera, Psychodidae). Cah ORSTOM, Sér Ent Méd Parasitol. 1972;55:239.

12. Randrianambinintsoa FJ, Leger N, Robert V, Depaquit J. Phlebotomine sand flies from Madagascar (Diptera: Psychodidae). VII. An identification key for Phlebotomus with the description of Phlebotomus (Anaphlebotomus) vaomalalae n. sp. Parasite. 2013;20:6.

13. Randrianambinintsoa FJ, Léger N, Robert V, Depaquit J. Paraphyly of the subgenus Sintonius (Diptera, Psychodidae, Sergentomyia): status of the Malagasy species. Creation of a new subgenus and description of a new species. PLoS One. 2014;9(6):e98065.

14. Cumming JM, Wood DM. Morphology and terminology. In: Manual of Central American Diptera. Edited by Brown BVea, vol. 1. Ottawa: NRC Research Press; 2009. p. 9-50.

15. Marcondes CB. A proposal of generic and subgeneric abbreviations for Phlebotomine sandflies (Diptera: Psychodidae: Phlebotominae) of the World. Entomological News. 2007;118:351-6.

16. Depaquit J. Molecular systematics applied to Phlebotomine sandflies: Review and perspectives. Infect Genet Evol. 2014;28:744-56.

17. Esseghir S, Ready PD, Killick-Kendrick R, Ben-Ismail R. Mitochondrial haplotypes and geographical vicariance of Phlebotomus vectors of Leishmania major. Insect Mol Biol. 1997;6(3):211-25.

18. Bonfield J, Staden R. Experiment files and their application during largescale sequencing projects. DNA Seq. 1996:6:109-17.

19. Thompson J, Higgins D, Gibson T. Clustal W: improving the sensivity of progressive multiple sequence alignment through sequence weighting, position-specific gap penalties and weight matrix choice. Nucleic Acid Res. 1994;22:4673-80.

20. Hall T. Bioedit: a user-friendly biological sequence alignment editor and analysis program for Windows 95/98/NT. Nucleic Acids Symp Ser. 1999;4:95-8.

21. Senghor MW, Faye MN, Faye B, Diarra K, Elquero E, Gaye O, et al. Ecology of phlebotomine sand flies in the rural community of Mont Rolland (Thies region, Senegal): area of transmission of canine leishmaniasis. PLoS One. 2011;6(3):e14773.

22. Kanjanopas K, Siripattanapipong S, Ninsaeng U, Hitakarun A, Jitkaew S, Kaewtaphaya P, et al. Sergentomyia (Neophlebotomus) gemmea, a potential vector of Leishmania siamensis in southern Thailand. BMC Infect Dis. 2013;13:333.

23. Rispail P, Léger N. Numerical taxonomy of Old World Phlebotominae (Diptera : Psychodidae). 1. Considerations of morphological characters in the genus Phlebotomus Rondani et Berté 1840. Mem Inst Oswaldo Cruz. 1998;93(6):773-85.

24. Rispail P, Léger N. Numerical taxonomy of Old World Phlebotominae (Diptera : Psychodidae). 2. Restatement of classfication upon subgeneric morphological characters. Mem Inst Oswaldo Cruz. 1998;93(6):787-93.

25. Polseela R, Apiwathnasorn C, Samung Y. Seasonal variation of cave-dwelling phlebotomine sandflies (Diptera:Psychodidae) in Phra Phothisat Cave, Saraburi Province, Thailand. Southeast Asian J Trop Med Public Health. 2007; 38(6):1011-5.

26. Polseela R, Apiwathnasorn C, Samung Y. Seasonal distribution of phlebotomine sand flies (Diptera: Psychodidae) in Tham Phra Phothisat temple, Saraburi province, Thailand. Trop Biomed. 2011;28(2):366-75.

27. Seccombe AK, Ready PD, Huddleston LM. A catalogue of Old World phlebotomine sandflies (Diptera, Phlebotominae). Occ Pap Syst Entomol. 1993;8:1-57 